\title{
60 years of Rabinowicz' criterion for adhesive wear
}

\author{
Elena POPOVA ${ }^{1,{ }^{*}}$, Valentin L. POPOV ${ }^{1, *}$, Dae-Eun KIM ${ }^{2,3}$ \\ ${ }^{1}$ Institute of Mechanics, Technische Universität Berlin, Berlin10623, Germany \\ ${ }^{2}$ School of Mechanical Engineering, Yonsei University, Seoul 03722, Republic of Korea \\ ${ }^{3}$ Center for Nano-Wear, Yonsei University, Seoul 03722, Republic of Korea \\ Received: 21 June 2018 / Revised: 04 August 2018 / Accepted: 06 August 2018 \\ (C) The author(s) 2018. This article is published with open access at Springerlink.com
}

\begin{abstract}
Ernest Rabinowicz published a 5 page paper titled "The effect of size on the looseness of wear fragments" where he suggested a criterion determining the minimum size of wear particles. The criterion of Rabinowicz is based on the consideration of the interplay of elastic energy stored in "asperities" and the work of separation needed for detaching a wear particle. He was probably the first researcher who explicitly emphasized the role of adhesion in friction and wear. In a recent paper in Nature Communications, Aghababaei, Warner and Molinari confirmed the criterion of Rabinowicz by means of quasi-molecular dynamics and illustrated the exact mechanism of the transition from plastic smoothing to formation of wear debris. This latter paper promoted the criterion of Rabinowicz to a new paradigm for current studies of adhesive wear. The size arguments of Rabinowicz can be applied in the same form also to many other problems, such as brittle-ductile transition during indentation, cutting of materials or ultimate strength of nano-composites.
\end{abstract}

Keywords: adhesion; plasticity; wear; Archard's law of wear; Rabinowicz criterion; surface topography; history of Tribology

\section{Introduction}

Ernest Rabinowicz is the author of one of the most influential books on friction and wear in the history of Tribology [1]. It appeared one year before the famous report of Peter Jost [2] and, together with it, marked the birth of Tribology. The mystery of the popularity and impact of the book of Rabinowicznot only among tribologists but also in engineering design-lies in its simplicity and the robustness of the concepts developed and presented by Rabinowicz. A persistent problem of Tribology is its poor "availability" - in this field there are practically no simple methods and concepts having high predictive power [3]. Rabinowicz succeeded in finding a small number of key concepts, rough at the edges but robust, which allowed for qualitative understanding of tribological properties and setting rules for tribological design. In the 1950s and 1960s, tribology was not yet mature enough for a detailed theoretical analysis or quantitative calculation of contact phenomena. Only a picture in the impressionist style could be drawn at the time-ignoring or distorting up close "details", but still presenting a coherent whole.

The name of Rabinowicz is deservedly associated with the role of adhesion in tribological processes. This was a backbone concept of his research and his book. For him, adhesion was the key concept for considering both friction and wear [4]. In considering wear, Rabinowicz distinguished the processes of material transfer from one partner to the other and of wear debris formation. Indeed, one of his most influential papers, co-authored with Tabor, is devoted to the radioisotope tracer study of metal transfer [5]. In later work, Rabinowicz extended his adhesion concept by introducing the notion of "similar" and

* Corresponding authors: Elena POPOVA, E-mail: elena.popova@tu-berlin.de; Valentin L. POPOV, E-mail: v.popov@tu-berlin.de 
"dissimilar" materials, which describes the tendency of material pairings to form alloys [6].

The main idea of how adhesion determines the process of wear was put forward by Rabinowicz in 1958 [7]. He assumed that the process of wear is governed by the interplay of elastic energy stored in a medium and the work of adhesion needed to separate two parts of a body-just as suggested by Griffith in his theory of crack propagation [8]. Griffith' idea was specified by Rabinowicz by equating the critical stress of crack propagation to the plastic flow stress. This modification allowed applying Griffith' idea to the problem of wear, but impeded any detailed analytical theory. Note that the general interest in adhesion in contact mechanics started only in the 1970s with the work of Johnson, Kendall and Roberts [9], so that in 1958 these ideas were ahead of time.

The lack of numerical possibilities at that time, Rabinowicz compensated with experimental work (Fig. 1), which he interpreted not by comparison with analytical or numerical solutions, but by carrying out correlation analysis, while the proper "coordinates" were determined using simple ideas and estimations.

The geometry of the problem of wear particle formation is much more involved compared to that of a crack, so that a simple analytical theory of particle

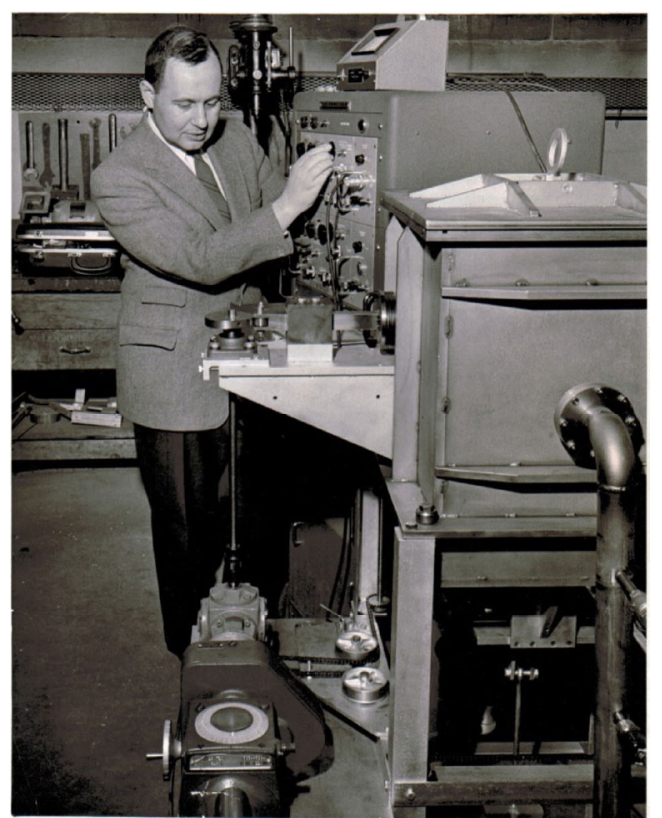

Fig. 1 Ernest Rabinowicz "hard at work". On this photo taken in the late 1950 s or early 1960s he is absorbed in work with a cylinder on cylinder rolling tester [10]. formation was not possible at that time and is not possible even now. It therefore remained "only an idea" for almost 60 years until Aghababaei, Warner and Molinari [11] carried out a numerical experiment very similar to the "thought experiment" of Rabinowicz of 1958.

While the basic idea of Rabinowicz from 1958 could only obtain the status of a verified paradigm 60 years after the fact, it was still developed during these years on a qualitative level. In the present paper, we try to follow the life of this idea in the years between 1958 and 2016.

\section{Rabinowicz' criterion for "looseness of wear particles"}

The initial idea formulated by Rabinowicz is very vague [7]. Following his experimental findings, he never speaks directly about wear particle formation but about two related processes - the material transfer from one body to the other one and the subsequent process of formation of loose particles and illustrates it by a sketch reproduced in Fig. 2 .

While the details of the processes described by Rabinowicz were left mostly unspecified, the central idea formulated by him does not depend on these details. He assumes that the wear fragment has a hemispherical shape and that it detaches after direct contact has been lost. The maximum elastic energy stored in the fragment during contact is of the order of $\frac{1}{2} \frac{\sigma_{Y}^{2}}{E} V$, where $E$ is the Young modulus, $\sigma_{Y}$ the yield stress of the fragment material, and $V$ the volume of the hemisphere. Since, after the loosing contact, only residual stresses remain in the fragment, Rabinowicz assumes that the elastic energy associated with these stresses is only around 0.1 (square of the Poissonnumber) of the maximum energy, so that the fragments will detach from the surface if this energy is sufficient for creating new surfaces with the area $A$ of the
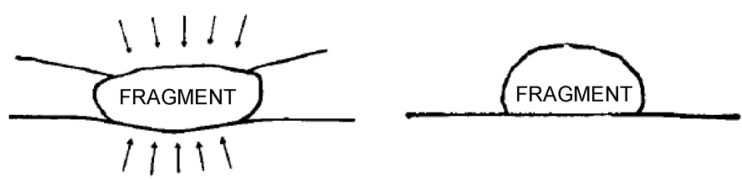

Fig. 2 Illustration of the formation of a "wear fragment" during contact and after losing contact [7]. 
hemisphere, which leads to the criterion

$$
\frac{1}{10} \frac{\sigma_{Y}^{2}}{E} \frac{\pi D^{3}}{12} \geq W \frac{\pi D^{2}}{4}
$$

where $W$ is the specific work of adhesion. Thus, only particles with diameter larger than the critical one,

$$
D>D_{c} \geq \frac{30 E W}{\sigma_{Y}^{2}}
$$

can detach spontaneously.

Thus initial idea of Rabinowicz was not about wear particle formation per se, but whether already formed particles will leave the surface after the immediate contact with the counter body is lost. In the same way he thought about the material transfer [12]. Note that from the point of view of the energetic criterion used, there is no difference between adhesion and cohesion. In other words, the Rabinowicz' criterion does not differentiate of whether the crack and detachment occurs along an interface between two different materials (adhesion) or inside a material (cohesion). In the latter case, only the specific work of adhesion, $W$, has to be replaced by the specific work of cohesion, $W_{c}$.

In a later work, Rabinowicz applied this criterion to a medium covered by a thin soft layer of a solid lubricant [13]. His theoretical arguments were very simple: Rabinowicz argued that there should be different wear mechanisms depending on whether the critical size of looseness of wear particles is larger or smaller than the thickness of the layer. Most interesting are his experimental results, which indeed show that there exists some critical thickness under which wear decreases drastically (Fig. 3).

In the paper [14], it was shown by direct application of a Rabinowicz-like energetic criterion to the problem of formation of a wear particle of a thin soft layer, that indeed there exists a critical thickness, below which the wear intensity decreases abruptly. Note that in Fig. 3 the vertical axis shows a quantity proportional to the life time (and thus inversely proportional to the wear intensity).

Rabinowicz always had a relatively complicated process of "wear fragment" formation in mind-due to both material transfer and detachment of particles. He was a practitioner and always proceeded from

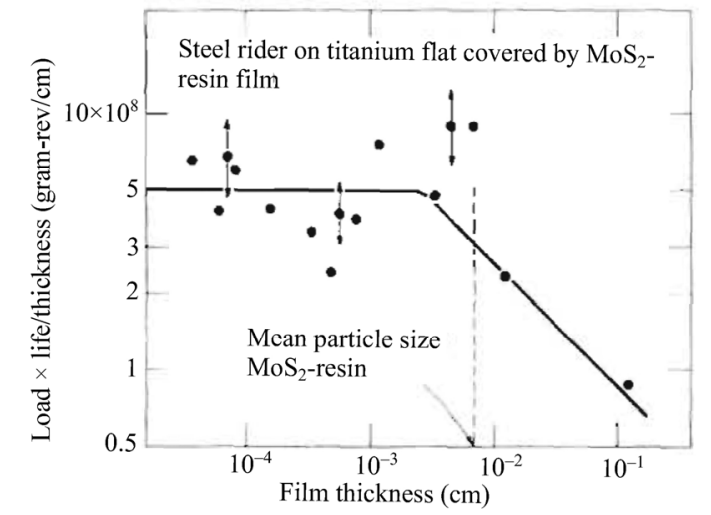

Fig. 3 The function load $\times$ life time/thickness plotted as a function of thickness for titanium flat surfaces lubricated by $\mathrm{MoS}_{2}$-resin (reproduced from Ref. [13]).

empirical observations and not from theoretical models. His work inspired many subsequent studies of this two-stage wear process, e.g., the experimental study [15], which appeared shortly after the paper [7] of Rabinowicz.

\section{Failure modes in a contact of two asperities}

The Rabinowicz criterion states that there are some conditions that must be fulfilled to make wear particle formation possible. But what happens when these conditions are not fulfilled (the junction size is smaller than the critical one)? Rabinowicz himself favored the idea of "atom-by-atom" removal, as opposed to wear debris formation. When speaking of such a process he uses the terms "burnishing" or "least wear" [16].

In the 60 years, there were many attempts to understand the mechanism of wear under conditions when free wear particles cannot be formed. For example, in Ref. [17], three types of failure modes of contact of two asperities are investigated using FEM analysis: shear, fracture and slip tongue.

Interestingly, a transition from plastic deformation to formation of wear particles also exists in the case of abrasive wear [18].

\section{Other applications of Rabinowicz' criterion}

The conclusion about the existence of a critical size 
applies not only to wear, but also to the strength of materials. The initial idea of Rabinowicz was related to the process of spontaneous detachment of a prestressed fragment of a material. This idea can be applied not only to fragments on the surface, but also inside the volume. If material has been intensively deformed plastically, it will have internal stresses on the order of the yield stress of the material, $\sigma_{\gamma}$. If the characteristic size of "structural elements" of the material is $D$, the material will spontaneously crack if the Rabinowicz criterion (2) is fulfilled. For smaller structural elements, spontaneous cracking is impossible. This leads to existence of some critical size of phases in composites, under which they become "crackresistant", and in particular tolerant to material flaws as shown by Gao et al. [19].

Absolutely the same "Rabinowicz"-like criterion arises in the problem of crushing small particles, where there exists a critical size

$$
d_{\text {crit }}=\frac{32 E W}{3 \sigma_{Y}^{2}}
$$

which coincides with the Rabinowicz criterion up to a constant coefficient [20]. If particles are smaller than this critical value, further crushing or pulverization is not possible. In the paper [20], Kendall writes further: "These size arguments are relevant not only for crushing but also to other processes connected with the brittleness and ductility of materials. For example, brittle substances may be indented plastically with a sharp tool, providing the indentation is below a certain size, above which cracking takes place. For calcium carbonate this critical size is $3 \mu \mathrm{m}$ [21], a value comparable with that calculated from Eq. (3). Another example is that of cutting, which can only occur if the depth of cut is sufficiently small to prevent cracking. Ductile machining swarf has been observed when glass was cut by very fine tungsten carbide tool [22]. The depth of cut when this became apparent was $0.5 \mu \mathrm{m}$, as compared with figure of $0.9 \mu \mathrm{m}$ from Eq. (3)".

Kendall's experiments with small particles reveal the "mechanism" of the brittle-ductile transition. The mechanism is obviously a competition between cracking and plasticity (Fig. 4). This transition does not automatically mean that very small particles are

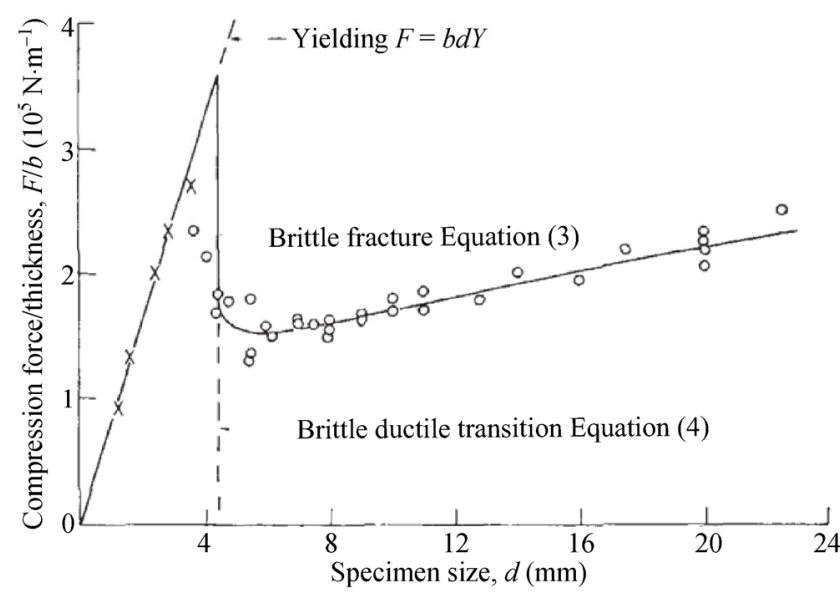

Fig. 4 Compression results obtained by K. Kendall for a range of specimen sizes illustrating cracking $\left(^{\circ}\right)$ for large samples and yielding $(\times)$ of small ones. Reproduced from Ref. [20].

especially strong. Figure 4 shows that decreasing of the particle size eventually leads to the decrease of the critical force of failure. Only the mechanism of failure changes from cracking to plastic deformation. This competition of plasticity and adhesion is discussed in detail in a "toy model" described in Ref. [23] showing that some plastic deformation generally occurs even in cases where cracking is the primary mechanism.

\section{Rabinowicz' criterion and Archard's wear equation}

The most popular law of adhesive wear states that the worn volume $V$ is proportional to the normal force $F_{\mathrm{N}}$ and the sliding distance $s$ and inversely proportional to the hardness $\sigma_{0}$ of the softer counterpart:

$$
V=k \frac{F_{\mathrm{N}} s}{\sigma_{0}}
$$

The constant $k$ is the so called adhesive wear coefficient. It is common to associate this wear law with the name of Archard. Even though similar formulations have been used before Archard's seminal work [24, 25], the law of adhesive wear deservedly carries his name-due to his enormous contribution to understanding the mechanics and physics of rough surfaces in contact. Rabinowicz used Archard's law and discussed adhesive wear in terms of the adhesive wear coefficient as the only reliable tool available. 
However, already the fact that the adhesive wear coefficient can vary over seven orders of magnitude shows that Archard's law (4) can only be a very crude approximation. All not-well-understood details are just gathered in the empirical adhesive wear coefficient. Already several decades ago it was clear that neither of the dependencies of Archard's law is universal. Thus, Rhee [26] has shown in 1970 that the dependence of the wear volume on the normal force is non-linear in most cases and can be better described by power-law dependencies.

Many different adjustments and alternatives to Archard's law have been proposed over time. The review of Meng and Ludema of 1995 shows hundreds of different wear "laws", none of which became widely recognized.

Note that Archard's law of adhesive wear does not include the surface energy as a parameter at all. However, the Rabinowicz criterion clearly implies that such dependence should appear at least under some conditions (for example if the size of junctions in contact becomes smaller than the critical one). A recent investigation shows clearly that application of the Rabinowicz criterion to the analysis of wear intensity leads to non-linear dependencies of wear volume on the normal force [28]. Note that introducing the surface energy as a possible governing parameter of the wear equation necessarily also leads to nonlinear dependence on the force and even the sliding distance. Experiments and dimensional analysis carried out in Ref. [29] suggest the following power law

$$
V=k \frac{W^{1,775}}{E^{3.225}} F_{\mathrm{N}}^{1.47} L^{1.25}
$$

Equations of this type may be of much higher value than Archard's law of wear, as they implicitly contain a dependence on surface energy and thus provide an estimation for the adhesive wear coefficient.

\section{Adhesion versus plowing model of friction}

The adhesion theory of friction and wear advocated and developed by Rabinowicz did not prevail without a challenge. Another school of thought regarding the origin of friction stemmed from the view that, rather than adhesion, mechanical interaction that occurs between two solids during sliding can be a more dominant factor in dictating the frictional behavior. This notion was ironically, or quite suitably, proposed by Nam P. Suh who was Rabinowicz's colleague at MIT. In the paper published by Suh on the topic of genesis of friction, friction was expressed as the sum of three components: asperity deformation, plowing and adhesion [30]. Of these three components, it was suggested that plowing was the most dominant factor in many metallic sliding systems. This reasoning was derived from the experimental data obtained from numerous friction tests conducted using identical and different metals. The fact that friction coefficient varied with sliding history was a key observation that led to the belief that adhesion alone could not be the dominating factor in dictating the frictional behavior of a sliding system. Furthermore, the typical increasing trend in the friction coefficient with increasing sliding distance suggested that as wear particles are created, surfaces get plowed by the strain hardened particles, which in turn contributes to the drastic increase in friction. Such experimental evidence disproved the fundamental concept behind Rabinowicz's compability chart that was constructed based on the thought that since friction is caused by adhesion, friction between identical or similar materials will be higher than that between dissimilar materials [1]. According to Suh, whether the materials in contact are identical or not, friction can be high due to wear particles that act to plow the contacting surfaces during sliding. As we know today, certainly both mechanisms play important roles on generating friction depending on the nature of the sliding system and conditions.

The contrasting views regarding the dominating friction mechanism between Rabinowicz and Suh instigated the tribology community on the topic of the origin of friction in a positive manner in the years to come. Such a debate on the dominant mechanism of friction prevailed not only in the professional community but also in the classrooms at MIT. Tribology was a graduate course offered at MIT Mechanical Engineering Department which was taught by both Rabinowicz and Suh. The students were excited by the opportunity to learn from these two great minds in the field who used their own books for the lectures: Friction and Wear of Materials by Rabinowicz [1] and 
Tribophysics by Suh [31].

It was through a classical topic such as friction from which the students were exposed to conflicting views and arguments. For many, this served as a motivation to go into the field of tribology, which at that time, unlike many other disciplines in mechanical engineering, still seemed to offer the opportunity for new theoretical developments and challenges. Students who were honored by the presence of both Rabinowicz and Suh in their Ph.D. thesis committee examinations were often overwhelmed with the burden to satisfy both of them with different views on friction. Nevertheless, the professors seemed to derive satisfaction from providing such a harsh and challenging environment to the students, who ultimately benefited tremendously from such an experience.

Rabinowicz's philosophy towards student education may be further evidenced by his policy on accepting a consulting job. He once told the students that he only accepts consulting jobs if the problem is interesting enough and at the same time sufficiently challenging to be applied to Ph.D. qualifying exams. This indeed demonstrates Rabinowicz's deep passion for breeding future generation tribologists as well as to the field of tribology to which he contributed greatly.

\section{Discussion and conclusion}

Ernest Rabinowicz takes a very special place in Tribology. He was a practitioner, which determined his widely empirical approach to tribological phenomena. He successfully managed to find a small number of key concepts, which allowed a very rough but robust and useful interpretation of a large amount of empirical data. He often used correlation analysis presented in double logarithmic coordinates, as many interrelations in Tribology can only be seen if one disregards the details and looks at the very rough picture. A very typical example of analysis by Rabinowicz can be read in his famous book when discussing the role of hardness in wear ([1], 6.22 Materials to be used in adhesive wear). Rabinowicz writes: "In the use of hard materials, it should be pointed out the wear rate does not generally produce very drastic effects. Suppose that we have an alloy steel which half-hard has a Rockwell $C$ value of $40\left(\sim 400 \mathrm{~kg} / \mathrm{mm}^{2}\right)$ and when fully hard has a Rockwell $C$ hardness of 80 $\left(\sim 800 \mathrm{~kg} / \mathrm{mm}^{2}\right)$. This difference by a factor of two in hardness will produce a difference by a factor of two in the adhesive wear rate, which is only just large to be measurable, since difference between repeat tests under identical conditions is likely to be a factor of 3!".

In part, it was this concentration on general dependencies (neglecting "fluctuations" by a factor of 3!) that allowed Rabinowicz to achieve such general understanding of tribological phenomena. His book is not only cited but it is actively used in practice-a very rare phenomenon in the tribological literature.

Now, 60 years after Rabinowicz formulated a basic model for adhesive wear, his concepts transform to paradigms for detailed model wear analysis based on new computational and experimental capabilities.

\section{Acknowledgement}

The authors thank Judith Raymond née Rabinowicz for providing a photo of Ernest Rabinowicz working in his lab.

Open Access: The articles published in this journal are distributed under the terms of the Creative Commons Attribution 4.0 International License (http://creativecommons.org/licenses/by/4.0/), which permits unrestricted use, distribution, and reproduction in any medium, provided you give appropriate credit to the original author(s) and the source, provide a link to the Creative Commons license, and indicate if changes were made.

\section{References}

[1] Rabinowicz E. Friction and Wear of Materials. Second Edition. John Wiley \& Sons, inc., 1995 (First Edition 1965).

[2] Jost H P ed. Lubrication (tribology)-A report on the present position and industry's needs. Department of Education and Science, H. M. Stationary Office, London, UK, 1966.

[3] Popov V L. Golden age of tribology? Grand challenges in tribological education and research. Frontiers in Mechanical Engineering, Section Tribology, 2018.

[4] Rabinowicz E. Influence of surface energy on friction and wear phenomena. Journal of Applied Physics 32(8): 14401444 (1961) 
[5] Rabinowicz E, Tabor D. Metallic transfer between sliding metals: An autoradiographic study. Proceedings of the Royal Society A: Mathematical, Physical and Engineering Sciences 208(1095): 455-475 (1951)

[6] Rabinowicz E. Friction coefficients of noble metals over a range of loads. Wear 159(1): 89-94, (1992)

[7] Rabinowicz E. The effect of size on the looseness of wear fragments. Wear 2: 4-8 (1958)

[8] Griffith A A. The Phenomena of Rupture and Flow in Solids. Philosophical Transactions of the Royal Society of London A 221: 163-198 (1921)

[9] Johnson K L, Kendall K, Roberts A D. Surface energy and the contact of elastic solids. Proc. R. Soc. London A 324: 301-313 (1971)

[10] Photo provided by Judith Raymond née Rabinowicz from family archiv.

[11] Aghababaei R, Warner D H, Molinari J-F. Critical length scale controls adhesive wear mechanisms. Nature Communications 7: 11816 (2016)

[12] Rabinowicz E. The Nature of the Static and Kinetic Coefficients of Friction. Journal of Applied Physics 22(11): 1373-1379 (1951)

[13] Rabinowicz E. Variation of Friction and Wear of Solid Lubricant Films with Film Thickness. ASLE Transactions 10(1): 1-9 (1967)

[14] Popov V L. Adhesive wear: Generalized Rabinowicz' criteria. Facta Universitatis, Series: Mechanical Engineering 16(1): 29-39 (2018)

[15] Cocks M. Interaction of Sliding Metal Surfaces. Journal of Applied Physics 33(7): 2152-2161 (1962)

[16] Rabinowicz E. The least wear. Wear 100: 533-541 (1984).

[17] Keer L M., Xu Y., Cheng H S., and Xuan, J L. Simulation of Wear Particle Creation in Asperity Contacts Using the Finite Element Method. Tribology Transactions 36(4): 613-620 (1993)

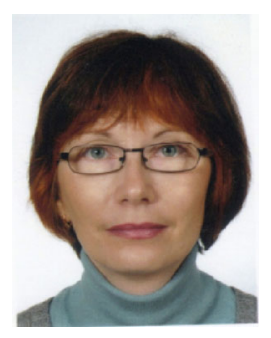

Elena POPOVA. She studied Slavistics at the Tomsk State University, Russia (graduated 1987 with degree Dipl.-Phil.) and German literature studies and Philosophy at the University of Paderborn, Germany (graduated 2003 with
[18] Yin X., Komvopoulos K. A slip-line plasticity analysis of abrasive wear of a smooth and soft surface sliding against a rough (fractal) and hard surface. International Journal of Solids and Structures 49(1): 121-131 (2012)

[19] Gao H, Ji B, Jager I L, Arzt E, Fratzl P. Materials become insensitive to flaws at nanoscale: Lessons from nature. Proceedings of the National Academy of Sciences 100(10): 5597-5600 (2003)

[20] Kendall K. The impossibility of comminuting small particles by compression. Nature 272(5655): 710-711 (1978)

[21] Shaw M C. Plastic flow in the cutting and grinding of materials. Proceedings of the National Academy of Sciences 40(6): 394-401 (1954)

[22] McClintock F A, Argon A S. Mechanical Behaviour of Materials. Reading USA: Addison Wesley, 1966, 495 p.

[23] Popov V L. Generalized Rabinowicz' criterion for adhesive wear for elliptic micro contacts. AIP Conference Proceedings 1909: 020178 (2017)

[24] Archard J F. Contact and rubbing of flat surfaces. Journal of Applied Physics 24: 981-988 (1953)

[25] Archard J F, Hirst W. The wear of metals under unlubricated conditions. Proc R Soc London A 236: 397-410 (1956)

[26] Rhee $S \mathrm{~K}$. Wear equation for polymers sliding against metal surfaces. Wear 16(6):431-45 (1970)

[27] Meng H C, Ludema K C. Wear models and predictive equations: their form and content. Wear 181: 443-457 (1995)

[28] Popov V L, Pohrt R. Adhesive wear and particle emission: Numerical approach based on asperity-free formulation of Rabinowicz criterion. Friction in press, DOI 10.1007/ s40544-018-0236-4.

[29] Kar M K, Bahadur S. The wear equation for unfilled and filled polyoxymethylene. Wear 30(3): 337-348 (1974)

[30] Suh N P, Sin H-S. The Genesis of Friction. Wear 69: 91-114 (1981)

[31] Suh N P. Tribophysics. Prentice-Hall, 1986.

degree Magistra Artium). She worked at the Tomsk Pedagogical University, Russian Academy of Sciences and later at the University of Potsdam. Since 2007, she coordinated double degree programs in Engineering Science with Russia and China at the Berlin University of Technology and carried out research in the field of history of tribology. 


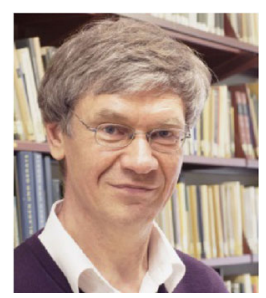

Valentin L. POPOV. He is full professor at the Berlin University of Technology. He studied physics and obtained his doctorate in 1985 from the Moscow State Lomonosov University. 1985-1998 he worked at the Institute of Strength Physics and Materials Science of the Russian Academy of Sciences and was a guest professor in the field of theoretical physics at the University of Paderborn (Germany) from 1999 to 2002. Since 2002 he is the head of the Department of System Dynamics and the Physics of Friction at the Berlin University of Technology. He has published over 300 papers in leading international journals and is the author of the book "Contact Mechanics and Friction: Physical principles and applications" which appeared in three editions in German, English, Chinese, and

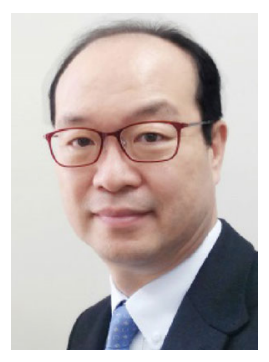

Dae-Eun KIM. He is currently a professor in the School of Mechanical Engineering and the Director of the Center for Nano-Wear (CNW) at Yonsei University. Prof. Kim received his B.S. degree from Tufts Univ., and M.S. and Ph.D. degrees from M.I.T. He was an assistant professor at the Ohio State University before joining Yonsei
Russian. He is the member of editorial boards of many international journals and is organizer of more than 20 international conferences and workshops over diverse tribological themes. Prof. Popov is honorary professor of Tomsk Polytechnic University, of East China University of Science and Technology, and of Changchun University of Science and Technology and distinguished guest professor of Tsinghua University. His areas of interest include tribology, nanotribology, tribology at low temperatures, biotribology, the influence of friction through ultrasound, numerical simulation of contact and friction, research regarding earthquakes, as well as topics related to materials science such as the mechanics of elastoplastic media with microstructures, strength of metals and alloys, and shape memory alloys.

University in 1993. He served as the Editor-in-Chief of IJPEM and Senior Editor of JMST. He is currently the President of the Korean Tribology Society and also serves as the Chair of the Technical Committee for Tribology of International Federation for the Promotion of Mechanism and Machine Science (IFToMM). His research interests are micro/nano-tribology, functional coatings, and surface modification techniques. 